\title{
Exploring Mental Models Of Construction Managers
}

\author{
Amlan Mukherjee ${ }^{1}$, Eddy M. Rojas ${ }^{2}$ and William D. Winn ${ }^{3}$ \\ ${ }^{1}$ Doctoral Candidate, Department of Civil and Environmental Engineering, University \\ of Washington, Seattle \\ ${ }^{2}$ Associate Professor, Department of Construction Management, University of \\ Washington, Seattle \\ ${ }^{3}$ Professor, College of Education, University of Washington, Seattle
}

\begin{abstract}
Experience is a critical component of expertise for construction managers. Time allows them to inductively construct and organize knowledge about the construction management domain that often cannot be easily formalized. The goal of this study was to investigate the nature of expertise in construction managers. Both experts and novices represent and organize experientially gained knowledge as abstractions that we refer to as "mental models". We investigated expertise by exploring mental models of construction managers. In this study we explored experimentally the existence of a difference in the mental models among construction managers.

A group of construction managers with varying levels of experience were asked to respond to a construction management crisis scenario. Using the ConProFac software to calculate an index $i$ indicative of the structuredness of the responses we found a significant correlation between $i$ and the number of years of experience of the respondent.

A better understanding of the mental models of experienced construction managers will help in developing a better theoretical understanding of the CM domain, while also enriching the construction management educational experience.
\end{abstract}

\section{Keywords}

Mental models, construction manager cognition, education, parallel distributed processing

\section{Introduction}

Construction managers build expertise through experience. Experience at handling unique real life project scenarios allows them to assimilate patterns of information and inductively construct and organize knowledge about the construction management domain that cannot be easily formalized or perceived analytically. In critical situations they tend to isolate, recognize and match the pattern of the problem at hand with familiar patterns that they have encountered before. Novices on the other hand tend to concentrate on the surface features of the problem at hand. 
Experiential learning allows expert construction managers to develop an intuition that sets them apart from novice construction managers. There is provocative evidence in Education literature to support the above claim. Studies of experts and novices in Physics (Chi et al. 1982), exploring organization of knowledge structures have found that in representing a schema for an inclined plane novices tend to concentrate on the surface features of inclined planes, while experts connect the notions of the inclined plane with laws of physics and the conditions under which such laws apply. Experts notice features and meaningful patterns of information, which cannot be reduced to isolated facts and propositions but are instead 'conditionalized' to specific circumstances (Bransford et al. 2000). The process of conditionalizing allows experts to develop the "expertise" that guide their decision making processes. Experts also have the ability to retrieve information on a selective basis befitting the context of the problem at hand.

The goal of this study was to investigate the nature of expertise in construction managers. Both experts and novices represent and organize experientially-gained knowledge using abstractions that we refer to as "mental models". We investigated expertise by exploring mental models of construction managers. In this paper we explore the existence of a difference in the mental models of construction managers. A better understanding of the mental models of experienced construction managers will help in developing a better theoretical understanding of the CM domain. It will also lead to the development of better learning strategies for CM students en route to acquiring expertise of their own.

The knowledge gained from better understanding the mental models of construction managers will allow us to get a better awareness of the human interaction in the construction management domain. Typically, the study of construction management concentrates on the interaction of resources within temporal constraints. This will help us better understand how human decision making impacts resource interaction in the CM domain. Critical decision-making in the face of crisis scenarios greatly contributes to the success of a construction project. A comprehension of mental models of experienced construction managers will allow us to shape CM curriculum and methods of practice in a way that will allow us to retain the knowledge of experienced construction managers even after they have retired.

\section{Mental Models}

More than fifty years ago, Craik (1943) suggested that the mind constructs "smallscale models" of reality that it uses to anticipate events (Johnson-Laird and Byrne 2000). Such models are conceptualizations of the world that the mind builds by incorporating the individuals' views of the world, of themselves, of their own capabilities and of the tasks that they are required to perform (Norman 1983) and are referred to as mental models. Individuals construct mental models of themselves and the environment that they are required to interact with from perception, imagination, the comprehension of discourse, or, more importantly for this study, as they solve problems. Mental models provide predictive and explanatory power for the understanding of such interaction, and experts, unlike novices, have them already in place to draw on. They underlie visual images, but they can also be abstract representations of situations that cannot be visualized. 
Mental models research is fundamentally concerned with understanding human knowledge about the world (Stevens and Gentner 1983). Specifically, scientists have studied mental models to explicitly reveal human understanding of limited content domains. Hutchins (1983) has used mental models in explaining the cognitive structures involved in Micronesian navigation techniques. De Kleer and Brown (1983) developed a framework for investigating the structure of people's mental models of physical devices. Other related work on expert cognition includes Chi et al. (1988) investigation into the nature of expertise and Noice's (1997) investigation into the expertise of professional dancers.

The shift from novice to expert is a shift from one system of beliefs about the world, one set of concepts and one set of problem solving capabilities to another (Wiser and Carey 1983). We believe that such a shift is in essence a shift in the underlying mental models of novices and experts. By studying the differences in the mental models of novice and expert construction managers, we can start understanding the critical differences in their problem solving approaches.

\section{Methodology}

Traditionally, mental models research focuses on either developing a knowledge representation for a particular domain or a phenomenological understanding of human thinking. The former method involves the development of knowledge representation networks using computer simulations, while the latter involves the psychological experimentation (Stevens and Gentner 1983). Meanwhile, research on novice-expert shift has been characterized by two approaches: diagnosis of novices' systematic misconceptions about content and how that affects problem-solving and differences in information processing analyses of problem solving procedures between experts and novices (Wiser and Carey 1983).

We have used a methodology that analyses the differences in problem solving approaches of novice and expert construction managers. This involves testing human subjects and quantitatively studying the results using ConProFac, a program that creates descriptions of how people organize their ideas and qualitatively analyzing their responses.

We gave a group of 7 construction managers, with different levels of experience, a construction scenario and documented and analyzed their reactions to the scenario at hand. The scenario described the construction of a $\$ 104$ million project of a stateof-the art library facility, to be built over a period of 24 months. The scenario was based on real life construction projects, and was developed in collaboration with GLY Construction, a Seattle based general contractor.

The information provided in the scenario included relevant project information like schedule and budget information, project participants, current delay on the project, recent information exchanges with the owner, budgetary constraints and space constraints on project site. (Complete project scenario is available at http://staff.washington.edu/amlan/survey/survey.html.)

The participant assumed the role of a construction manager with First Construction, a GC/CM 'At-risk' contractor. The project scenario presented the participant with a $60 \%$ completed project that should have been $67 \%$ completed at the time of the situation. The project had been delayed due to an "act-of-God" event, a 
snow storm. The owner, the City of Seattle, had in response provided a 15-day extension on the schedule after which First Construction would face liquidated damages of $\$ 15,000$ per day of delay. In order to finish by the new deadline, First would need to complete installation of curtain walls on schedule to enable the interior decoration sub to finish on time.

First Construction had been brought onto the project because of their reputation in curtain wall installations. However, clerical errors in specifying the nature of the prefabricated curtain wall material requirements had resulted in delivery of inappropriate material. Space constraints demanded that the delivered material be installed to avoid delay on the project. Labor constraints threatened a situation in which First Constructon would not have access to skilled labor because of a delay in the wall installation and the constraints on cost and schedule had to be attended to, while maintaining the reputation of First Construction.

The participant was required to analyze the information that had been provided and devise the "best possible plan of action" subject to the situational constraints. Based on their plan they were required to respond to a set of questions that required them to explain their plan of action and justify their priorities. Information about the project provided in the scenario was incomplete and insufficient to answer all the questions in the questionnaire. However, the ambiguity had been deliberately designed as we expected the participants to answer the questionnaire based on what they intuitively felt about the situation at hand. They were encouraged to make suitable assumptions and draw conclusions based on them writing all their assumptions in the space provide.

We identified four distinct areas of concern: Space Management, Schedule Management, Labor Management and Materials Management. For each of these areas, each participant was required to indicate briefly his/her plan of action, using available information. For example a decision to "hire skilled laborers" would be a plan of action to "manage labor," while a decision to "crash activity X" would be a plan of action to "manage schedule. " Participants were also required to rank, on a scale of 1-10, how they believed their "plans of action" would affect the project schedule, project cost and the reputation of the company, for each of the four areas of concern listed above. A value lower than 5 would indicate an adverse impact, while a value higher than 5 would indicate a positive impact. A value of 5 would indicate maintaining the "as-planned" schedule.

We used the ConProFac software to calculate an index $i$ indicative of the structuredness of the numerical responses, while qualitatively analyzing the plans of action that the participants keyed in. In the following section we have briefly discussed how the ConProFac software works and how we utilized it to analyze the user inputs.

\section{Conprofac}

The ConProFac program creates descriptions of how people organize their ideas about a content area at different levels of generality: CONcepts, PROpositions or FACets. It can be used with any information about how collections of concepts are connected by predicates to form propositions. For example, "cat" and "mammal" are connected by "is a" to form the proposition, "cat is a mammal," or "bad weather" and 
"construction delays" can be linked causally to give, "bad weather causes construction delays." The truth of propositions about concepts can either be binary, that is either true or false, or weighted to express the likelihood that the proposition is true, or that a participant believes it to be true.

Propositions and their associated values can be obtained in a number of ways. The simplest one is to ask subjects to rate the truth of a set of propositions on a scale. Data can also be gathered from distance metrics applied to concepts placed at nodes in concept maps, whose inter-node connections are named, from free verbal associations given to sets of concept names, and even from analysis of freely-composed text. ConProFac can either create tables of proposition values from the propositions themselves, entered as strings, or can accept numerical tables directly that have been prepared by the researcher.

ConProFac uses standard methods (for example, see Rumelhart \& McClelland, 1986) to calculate the strengths of associations ("weights") in a network among all the concepts in the content area, and to place them in a matrix. These weights express the probability that if one concept becomes "active", others will too. The network can then be queried, by activating a single concept or a group of them, to determine which concepts are associated with which others and how strongly. Also, the network can be trained to recognize patterns.

Most relevant to this study is the comparison of the pattern of weights across matrices derived from individual subjects. ConProFac calculates the structuredness index $i$ that can be used to compare differences among the ways subjects organize their ideas and how these change over time, using standard statistical procedures. The value of $i$ always lies between 0 and 1. A mental model that reflects a very high level of structuredness with absolutely no ambiguity would have $i=1$, while a mental model which is completely ambiguous and incapable of exhibiting any consistently structured response would have $i=0$.

We constructed a three by four matrix to tabulate the participant's responses regarding how they thought of their "plan of action," with respect to the four areas of concern identified namely, space, schedule, labor and material management effected project cost, project schedule and company reputation. We analyzed each of these matrices using ConProFac to calculate the structuredness index $i$ for each of the participants by using their numerical inputs as indications of how important they thought the sensitivities were of each of the matrix items. Analysis of the data as explained in the following section and the value of $i$ allowed us to analytically understand the mental models of the participants.

\section{Results}

The following table lists the relevant statistics generated from the participant responses, the values of $i$, the time taken by the participant to complete the responses, and the experience (in years) of each of the participants.

The data listed in the above table have been plotted in Figure 1 for each participant. The question is, what kind of statistical correlation exists between experience and the structuredness index of the participants, and how reliable are the available data points. We used a third metric, the time taken by each participant in completing the responses after having read the scenario to assess the reliability of 
their response. As is obvious from the table, the rather short interval of time taken by participant 7 and the rather long interval of time taken by participant 1 clearly attract attention.

Table 1: Structuredness Index, Experience (in years) and time taken (in minutes) of each participant

\begin{tabular}{|c|c|c|c|}
\hline $\begin{array}{c}\text { Participant } \\
\#\end{array}$ & $\begin{array}{c}\text { Structuredness } \\
\text { Index }(0<i<1)\end{array}$ & $\begin{array}{c}\text { Experience } \\
\text { in Years }\end{array}$ & $\begin{array}{c}\text { Time } \\
\text { Taken(mins })\end{array}$ \\
\hline 1 & 0.685 & 19 & 41.09 \\
\hline 2 & 0.512 & 10 & 14.37 \\
\hline 3 & 0.968 & 18 & 10.42 \\
\hline 4 & 0.50 & 10 & 19.31 \\
\hline 5 & 0.512 & 7 & 22.37 \\
\hline 6 & 0.609 & 8 & 16.03 \\
\hline 7 & 0.50 & 14 & 4.06 \\
\hline
\end{tabular}

It is clear from the responses of participants one and seven, that participant seven took a very short while to complete the test (indicating possible lack of interest) and that participant one has provided detailed involved replies. Hence, in calculating the correlation coefficient we have excluded participant 7 . The correlation coefficient so calculated is 0.77 . If we do discount participant one and seven as extreme cases, we get an even higher correlation coefficient of 0.90 .

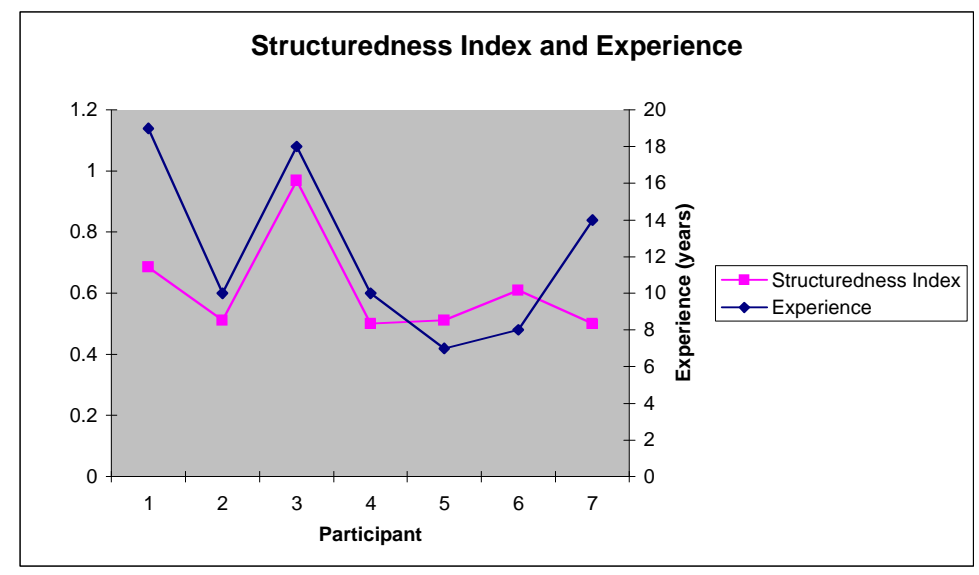

Figure 1: Structuredness Index and Experience of each participant

Qualitative analysis of the participants "plans of action" shed more light on the differences in the mental models of experts and novices.

The responses of participants one and three both with comparable lengths of experience have the following in common:

- Enumeration of possible situations that might arise from the scenario and expectations of outcomes from such possibilities e.g.: 
First I would approach the owner to determine if they would accept the incorrect glass. I would assess the time it would take to replace the glass and determine the impact to the schedule and the extent of further liquidated damages (Participant 1)

1. Review whether materials can be more efficiently organized on site to allow continued storage of glazing materials.

2. Review costs for an off-site warehouse to store the materials.

3. Review whether local installer has space in their warehouselyard to store materials. (Participant 3)

This is markedly different from responses of participants with fewer years of experience, who emphasize more on what needs to be done immediately to solve the problem at hand, e.g.:

The glass that is not correct should either leave the site or be installed in order to close the building in. (Participant 5)

Throw away the glass since it is defective. this will provide area for the other subs to store materials (Uninvolved Participant 7)

Call surrounding parking lots and/or open spaces to see if space can be secured. Look at roof space, possibly haul other material to our yard and have our own forces deliver the material, possibly at night time where streets could be possibly used (blocked off). (Participant 2)

- Off the cuff calculations to support and evaluate decisions e.g.:

The 7\% delay represents approximately 35 day delay after the 15 day extension is taken. This is approximately \$525,000.00 in LD. In addition, a month of general contractor overhead (at First Co.) expense would be about $\$ 65,000$ that cannot be recovered. Clearly, any steps to improve the schedule are very important. (Participant 1)

Based on the above observations we can say that, with experience, construction managers tend to base their decisions and plans on apprehensions of different possible outcomes of current situations. They also tend to support their decisions by rough calculations using thumb rules, even in situations with incomplete information. The thumb rules that they use are usually based on cost patterns that they tend to recall from previous project experiences. In contrast, managers with fewer years of experience tend to concentrate more on immediate actions without considering longterm impacts.

\section{Discussion andConclusion}

This paper presents the tip of an iceberg and is a preliminary investigation of mental models of construction managers. Based on our study, we can conclude that there exists a high correlation between levels of structuredness of thought and knowledge organization between expert and novice construction managers. This indicates that over periods of time, experience helps in fine-tuning the mental models of construction managers. A qualitative analysis also indicates that experts tend to apprehend the future impacts of their plans while deciding, as compared to novices. It also indicates that even in situations of limited information, experts tend to make 
"complete" calculations using rules of thumb drawn from situations that they have encountered before.

The significance of these results is not in their novelty, but in the fact that we can use mental models to analytically quantify the knowledge that comprises expertise among construction managers, which are difficult to formalize. There is a dictum that "expert construction managers often don't know what they know." This study provides us with methods that can be used to ascertain such knowledge.

Understanding the way experienced construction managers' work can be very useful in creating more meaningful curriculum in civil and construction engineering and management academic programs. For example, by the most part, the current construction management curriculum does not provide students with a platform to explore "what-if" scenarios on construction projects, or train them in long-term decision making. Studies like this should motivate changes in curriculum that provide students with a platform where they can test their decision making skills and be able to evaluate the long term impacts of decisions on cost and schedule The understanding that experienced decision-making requires long-term apprehension of impacts and events could in no small way direct research in developing interactive simulation environments that can allow students to get "virtual experience" and mimic the mental models of experienced professionals before they graduate.

That being said, this study is far from complete. The results are based on a sample of only seven construction mangers, all of whom work at the same construction management firm. Also, the data are correlational, which precludes conclusions about causal relationships between experience and struturedness. But it is important to understand that the study is examining a nascent topic and establishing correlation is a first step toward studies of causal relations. Also, the study goes a long way in setting the agenda for using mental models, a method that cognitive scientists have been using for a long time, to better understand the human and resource interaction in construction management. Long-term studies along these lines would require greater support and a collaborative environment shared by both universities and industry. Hence this study can be used as a springboard for further research in this field.

\section{Acknowledgement}

We are thankful to Mr. Ted Herb, Principal, GLY Construction, Seattle, WA for having kindly helped with his advice and valuable suggestions in undertaking this project.

\section{Reference}

Bransford, John D., Brown, Ann L. and Cocking, Rodney R. "How People Learn" National Academy Press, Washington D.C., 1999.

Carey, S. and Wiser, M. (1983) "When Heat and Temperature Were One," in Mental Models, Gentner, D. and Stevens, A.L., eds. Pp 267-298, Lawrence Earlbaum Associates, Publishers, Hillsdale New Jersey, 1983.

Chi, M., Bassok, M., Lewis, M., Reimann, P., and Glaser, R. (1989) "Selfexplanations: how students study and use examples in learning to solve problems," Cognitive Science, 13, 145-182. 
The Nature of expertise / edited by Chi, Michelene T.H., Glaser Robert, Farr, Marshall J. Pub info Hillsdale, N.J. : L. Erlbaum Associates, 1988

Craik, K. The Nature of Explanation. Cambridge: Cambridge University Press, 1943.

De Kleer, J and Brown, J.S. (1983) "Assumptions and Ambiguities in Mechanistic Mental Models," in Mental Models, Gentner, D. and Stevens, A.L., eds. Pp 155190, Lawrence Earlbaum Associates, Publishers, Hillsdale New Jersey, 1983.

Gentner, D. and Stevens, A.L (editors) Mental Models Lawrence Earlbaum Associates, Publishers, Hillsdale New Jersey, 1983.

Hutchins, E. (1983) "Understanding Micronesian Navigation," in Mental Models, Gentner, D. and Stevens, A.L., eds. Pp 191-226, Lawrence Earlbaum Associates, Publishers, Hillsdale New Jersey, 1983.

Johnson-Laird, Phil and Ruth Byrne (May 2000)

Website:http://www.tcd.ie/Psychology/Ruth_Byrne/mental_models/

The nature of expertise in professional acting: a cognitive view / Tony Noice, Helga

Noice Pub info Mahwah, N.J. : L. Erlbaum Associates, 1997

Norman, D. A. (1983) "Some Observations on Mental Models," in Mental Models,

Gentner, D. and Stevens, A.L., eds. Pp 7-14, Lawrence Earlbaum Associates, Publishers, Hillsdale New Jersey, 1983.

Rumelhart, D.E., \& McClelland, J.L. (1986). Parallel distributed processing: Explorations in the microstructure of cognition. Cambridge, MA: MIT Press. 